\title{
《地球物理学报》编委会会议纪要
}

在 2020 年中国地球科学联合学术年会期间,《地球物理学报》编委会于 10 月 19 日在重庆悦来国际会议 中心召开. 刘洪常务副主编主持了会议.潘永信主编、黄清华副主编、艾印双、常旭、陈棋福、底青云、高静怀、 胡祥云、黄金水、李斐、刘代志、孙建国等编委, 中国地球物理学会陈晓非理事长和郭建秘书长, 以及编辑部 胡素芳、汪海英参加了会议.

编辑部负责人何燕博士就学报 2019-2020 年度编辑出版情况、期刊影响力、存在问题及对策等方面做 了工作汇报. 学报 2019 年出版 12 期,发表 380 篇论文,共计 4885 页;2020 年(截至 10 月 20 日) 出版 10 期, 发表 299 篇论文,共计 3930 页. 本刊 2019 年度在 SCI 数据库中,影响因子 0.811 , 总被引频次 4768. 在编委 和编辑部的共同努力下,本刊成功人选了中国科技期刊卓越行动计划梯队项目 (2019-2023), 刊物影响力得 到进一步提升. 在过去一年中论文出版周期明显缩短. 如何吸引优质稿件仍是刊物的主要问题之一.

与会编委围绕如何提高刊物影响力建言献策, 提出了许多建设性的意见,包括进一步优化审稿流程和过 程质量控制, 加大推进责任编委送审, 缩短审稿周期等. 鼓励前沿领域综述和评述性论文,鼓励研究论文作者 增加研究结果的数据、模型、代码程序附录等.最后,潘永信主编对会议进行了总结,对各位编委表示感谢.会 议取得了圆满成功.

(《地球物理学报》编辑部)

\section{《地球与行星物理 (英文)》编委会会议纪要}

在 2020 年中国地球科学联合学术年会期间, 《地球与行星物理 (英文)》(Earth and Planetary Physics, 简 称 EPP) 编委会于 10 月 19 日在重庆悦来国际会议中心召开. 会议由常务副主编魏勇研究员主持. 中国地球 物理学会理事长陈晓非院士、秘书长郭建研究员、EPP 主编潘永信院士、编委张可可教授等 31 人参加了会 议. 陈晓非理事长高度赞扬了已故首任主编万卫星院士带领 EPP 取得的突出成绩,并表达了对 EPP 未来发 展的大力支持. 潘永信主编回顾了与万卫星院士一起创刊 EPP 的历程, 并表达了与编委会共同努力加快提 升期刊质量的信心.

期刊编辑部负责人胡素芳博士汇报了 EPP 一年来的主要工作. 在过去一年 EPP 期刊有长足的发展, 稿件 比前两年明显增多,尤其是空间和行星科学方面的稿件数量明显增加. EPP 先后组织了中国首次火星探测预研 成果、首次火星探测载荷、风云气象卫星成果等专题. EPP 被 ESCI 国际数据库和中国科学引文数据库 (CSCD) 收录，被国内的三大全文数据库 CNKI、万方、维普收录. 截止 2020 年 9 月 15 日,Web of Sciences (WOS)共收录 EPP 论文 164 篇,共引用 351 次.引用高的前 5 篇论文论文有: (1)Zhang X. M. 等的“An M6. 9 earthquake at Mainling, Tibet on Nov. 18, 2017”, (2) Ni B. B. 等的"Radiation belt electron scattering by whistler-mode chorus in the Jovian magnetosphere: Importance of ambient and wave parameters, (3) Balan Nanan 和 Liu L. B. 的“A brief review of equatorial ionization anomaly and ionospheric irregularities", (4)Zong Q. G. 等的“Corotating drift-bounce resonance of plasmaspheric electron with poloidal ULF waves", (5)Zheng T. Y. 等的“A seismic model for crustal structure in North China Craton”,等等. 依据贡献,评选了崔峻、张效信、杨宏锋、姚华建、乐新安等优秀编委 23 名,评选了史全岐、郝永强、薛向辉、葛亚松、李红谊等优秀审稿专家 35 名.

编委们就如何进一步办好 EPP 期刊提出了许多宝贵的意见和建议. 编委讨论了论文版面费收取、提高 论文英文写作水平、亮点论文等. 黄清华教授和汪毓明教授提出从单位评价政策层面支持 EPP, 提升期刊影 响力; 宋晓东教授提出地球物理学科的期刊共同发展的建议; 孙文科教授建议 EPP 进行专业评估,帮助期刊 尽快达到 SCI 收录要求; 王华沛教授和孔大力教授提出完善投稿质量的技术方面建议; 会议还讨论了围绕 热点研究领域和重要科研活动的组稿事宜. 会议取得了圆满成功. 